\title{
EL IUSFILÓSOFO EN LA COTIDIANIDAD Y EL QUÉ DE LA PREGUNTA: ¿QUÉ ES EL DERECHO?*
}

IMELDO CASTRO VILLENA**

Resumen: El pensamiento iusfilosófico no puede mantenerse a espaldas e insensible a los cambios sociales y a los paradigmas científicos, puesto que estos tienen la capacidad de influir en el sentido teórico y práctico del derecho y desbordan ampliamente el clásico horizonte normativo al que están acostumbrados los oficiales del derecho y los investigadores jurídicos. A la conciencia normativa se le debe inaplazablemente por lo menos sumar la "conciencia tecnológica" y la "conciencia digital", debido a que el modo de ser del derecho y del Estado de derecho se encuentra mediado por estas. Se transita hacia una transversalización tecnológica del derecho y hacia un modelo de "Estado de derecho electrónico".

Palabras clave: lusfilósofo, iusfilosofía, derecho y práctica jurídica.

\section{HACIA UNA NUEVA FORMA DE HACER FILOSOFÍA DEL DERECHO}

Los malos tiempos son siempre espacios propicios para renovar y reajustar la filosofía del derecho. La readaptación del quehacer iusfilosófico no supone el abandono de su contenido y de sus tradicionales categorías conceptuales, pero implica la ampliación tanto de su horizonte temático como de su cinturón conceptual. En este sentido, desde la iusfilosofía se tienen que problematizar y analizar los nuevos acontecimientos sociales y científicos —neurociencia, inteligencia artificial y paradigmas tecnológicos - que tienen impacto mediato e inmediato en el derecho. Asimismo, se debe emprender una reingeniería conceptual que se adecúe apropiadamente a ellos. En este caso, se crean figuras conceptuales o se flexibilizan las que ya se tienen. El pensamiento iusfilosófico no puede mantenerse a espaldas e insensible a los cambios sociales y a los paradigmas científicos, puesto que estos tienen la capacidad de influir en el sentido teórico y práctico del derecho, y desbordan ampliamente el clásico

\footnotetext{
* Artículo de investigación Número Especial de Aniversario. Recibido el 17 de abril de 2020 y aceptado para su publicación el 13 de julio de 2020.

** Docente invitado en la Facultad de Derecho de la Universidad Nacional de San Agustín, Perú. / imeldocastro@gmail.com / orcid.org/0000-0003-2248-1960
} 
horizonte normativo al que están acostumbrados los oficiales del derecho y los investigadores jurídicos. A la conciencia normativa se le debe inaplazablemente por lo menos sumar la "conciencia tecnológica" y la "conciencia digital", debido a que el modo de ser del derecho y del Estado de derecho se encuentra mediado por estas. Se transita hacia una transversalización tecnológica del derecho y hacia un modelo de "Estado de Derecho electrónico". ${ }^{2}$ El reajuste de la filosofía del derecho exige un acercamiento más íntimo a dicha realidad; graficado el asunto en términos económicos, conlleva a que la oferta de la filosofía del derecho tiene que estar graduada con la demanda social y tecnológica.

Es hora de que la filosofía del derecho y sus cultivadores peregrinen y participen de la metamorfosis social. Si durante el siglo XX se exigía que los teóricos del derecho tuvieran una formación humanística, ${ }^{3}$ en tiempos actuales la referida instrucción es insuficiente, y debe integrarse con un adiestramiento basado en contenidos de inteligencia artificial, avance tecnológico, neurociencias y filosofía de la mente. Únicamente así puede darse la perspectiva totalizadora —racional y crítica- de la iusfilosofía que ha propuesto Atienza. ${ }^{4}$

Para la cultura latinoamericana, acostumbrada a idolatrar las leyes y centrada exclusivamente en el estudio del derecho en su aspecto normativo, se debe indicar con ánimo atrabiliario que lo referido en el párrafo anterior es demasiado pedir. Si aún las humanidades no han conseguido arribar a la mayoría de los recintos de formación jurídica, menos lo harán el resto de las diciplinas contemporáneas; tal vez, reservando un poco de optimismo, puede que se adelanten a las humanidades. Ya el tiempo lo dirá.

\section{EL IUSFILÓSOFO EN LA COTIDIANIDAD Y LA IUSFILOSOFÍA EN LA PRÁCTICA}

El científico, en su laboratorio, observa a detalle las reglas que rigen su campo de acción; se comporta dentro de este ambiente conforme a los protocolos que requiere su actividad y trata de seguir al mínimo con todas las exigencias. Si ha

\footnotetext{
${ }^{1}$ El término conciencia tecnológica debe su paternidad a Frosini, Vitorio, // dirito nela società tecnologica, Giufrè, Milano, 1981.

${ }^{2}$ De manera simple y tradicional, se define al Estado de derecho como el gobierno de las leyes. Entiendo el Estado de derecho electrónico como el gobierno de las leyes con mediación de la tecnología.

${ }^{3}$ Fronsini, Vitorio, "El jurista en la sociedad tecnológica", trad. Fernando H. Llano Alonso, Revista Argumentos de la Razón Técnica, núm. 2 [consultado el 1 de mayo de 2020]. Disponible en: https://idus.us.es/handle/11441/2401.

${ }^{4}$ Atienza, Manuel, Introducción al derecho, Barcanova, Barcelona, 1989, p. 371.
} 
planteado alguna teoría, la explica y la defiende entre sus pares. En todas estas circunstancias, los materiales conceptuales que principalmente rigen su actuar son de origen científico, puesto que es hombre de ciencia y se comporta como tal. En cambio, al culminar sus quehaceres profesionales, al salir de su laboratorio y al terminar su conferencia, el científico deja de ser científico e ingresa a otro escenario existencial. Aquí, las normas que guían su accionar responden a otras categorías vitales. Su actividad profesional es separable de su forma de ser en sociedad. En su caso, esta dualidad o desdoblamiento es perfectamente comprensible y aceptable. No hay nada que reprocharle al científico.

Si embargo, lo indicado en el parágrafo anterior no debería suceder cuando se trata de aquellas personas que se dedican a reflexionar sobre teoría política, filosofía moral y filosofía del derecho. De presentarse la indicada dualidad, se hace insostenible y se torna incomprensible.

En el caso del filósofo del derecho, no puede conducirse, por un lado, como pensador o investigador del derecho; por otro lado, como ciudadano. Lo propio se espera de los aplicadores del derecho. Sus proposiciones teóricas, por muy abstractas que sean y aparenten cierta "objetividad" dentro del marco de la investigación jurídica y del derecho, no son —o en todo caso, no deberían serajenas a su existencia. El iusfilósofo actúa pensando. Su pensamiento arrastra su vida, lleva y guía su existencia.

Desde la filosofía moderna, quien retrata la conexión entre pensamiento y acción es Hegel; para él, por ejemplo, la distinción metodológica entre pensamiento y voluntad es aparente, en sustancia son inseparables. ${ }^{5}$ Sucede que los filósofos no únicamente han brindado expresiones teóricas respecto a la relación pensamiento-acción, sino que también han materializado hechos donde se observa un compromiso coherente entre lo teórico y la praxis, es decir, entre lo pensado y lo realizado. Sócrates ${ }^{6}$ es un prototipo que muestra que, cuando se reflexiona sobre asuntos que están comprometidos con el razonamiento práctico, no queda más remedio que actuar conforme a lo que se ha pensado. Sócrates

\footnotetext{
${ }^{5}$ Véase: Hegel, W. F., Fundamentos de la filosofía del derecho o compendio de derecho natural y ciencia política, trad. Joaquín Abellán García, Tecnos, España, 2017.

${ }_{6}^{6}$ Véase: Platón, Apología a Sócrates, trad. Juan Zaragoza, Gredos, España, 1993.
} 
demostró hasta en tres circunstancias considerables que su vida se ha conducido conforme sus exigencias teóricas. La primera se da cuando los treinta tiranos le ordenan que vaya a traer a León de Salamina para poder condenarlo a muerte; ante esta orden, él contesta con un concluyente: "no". Desobedece el mandato y retoma el camino a su casa. La segunda se presenta cuando el jurado decide perdonarle la vida siempre y cuando no insista en examinar a sus conciudadanos en el ágora. "Eso, ni pensarlo —dijo Sócrates-, pues tengo que mantenerme en mi posición, firme como un hoplita". La tercera se manifiesta cuando Critón le propone que escape de la cárcel para poder salvar su vida, a lo que Sócrates responde con un rotundo: "ni aceptarlo, ni hablar, eso es imposible". Imposible, no debido a la falta o carencia de condiciones para la fuga, sino porque así lo había determinado Sócrates.

Se encuentra muy asentada la equivocada consideración de que entre filosofía del derecho y praxis jurídica existe una separación irreconciliable. Ambas se presentan como una pareja dicotómica que, de alguna manera, configura algo parecido a la mitológica cabeza de Jano. Mientras los iusfilósofos dirigen maravillados la mirada al cielo estrellado, los operadores del derecho no pretenden en lo más mínimo levantar sus pesadas miradas de la tierra. Los que tienen contacto directo con la práctica del derecho advierten que a los iusfilósofos no les interesan los problemas jurídicos concretos y que centran sus reflexiones en torno a temas abstractos y generales.

Buena parte de los oficiales del derecho piensan erróneamente que la iusfilosofía nada tiene que enseñarles en su labor; consideran que los resultados que se obtienen a nivel de ella no contienen criterios que sean capaces de orientar y reconfigurar la práctica jurídica, puesto que las conclusiones a las que arriban casi siempre son argumentos que no poseen la fuerza de la canonizada silogística que los oficiales del derecho prefieren con mucha simpatía y a la que están acostumbrados. Cuando desean aclarar su pensamiento, recurren inmediatamente a la norma jurídica y a la jurisprudencia, pues no advierten que la iusfilosofía también puede cumplir una función similar, ya que no se agota en ser un simple ejercicio argumentativo y retórico. Si bien es cierto que el conocimiento que produce es general y abstracto, no es indiferente a la praxis del derecho. Su función no tiene por qué terminar en la clarificación de los 
conceptos más trascendentes del derecho, también puede ser orientadora de la práctica jurídica.

Como actividad académica, la filosofía del derecho se vuelca a la abstracción y a la generalidad debido a la influencia del derecho natural de fines del siglo XVIII; en este sentido, Carpintero, en su texto La cabeza de Jano, señala que durante el siglo XVII los iusnaturalistas se enfocaron en analizar problemas jurídicos sustantivos y concretos, pero a medida que avanzaba el siglo XVIII los estudiosos iusnaturalistas se inclinaron de manera preferencial al análisis y estudio de cuestiones generales. Esta situación ha hecho que el derecho natural sea considerado como una teoría general de la ética, de modo que el derecho natural dejó de proporcionar pautas configuradoras de la realidad social y pasó paulatinamente a convertirse en una "filosofía del derecho" ocupada en temas puramente abstractos. ${ }^{7}$

El derecho, como resultado de un proceso histórico y social, responde a la realidad y opera con categorías que tienen incidencia directa en la vida del ser humano. El quehacer del iusfilósofo tiene su punto de partida en ese complejo de hechos que se originan en la cotidianidad de la existencia humana. El derecho trata de lo cotidiano y la iusfilosofía lo abraza.

¿Qué derecho tengo en un determinado caso? ¿Qué obligación me exige el Estado? ¿Qué es la certeza jurídica? Son preguntas que permean en una realidad concreta. La filosofía del derecho se ocupa de ellas con la finalidad de conseguir posibles respuestas a los problemas que se generan en la sociedad, esto hace que el quehacer iusfilosófico no quede reducido a una actividad interpretativa de lo conceptual; no obstante, esto no implica que se deba ir en contra de la fijación conceptual, pues esta también forma parte de la labor iusfilosófica.

Por lo tanto, constituye un error afirmar o pensar que la iusfilosofía termina siendo tan solo una actividad contemplativa e incapaz de sobrepasar la mente del iusfilósofo, los recintos universitarios y los textos académicos. Quien propone una teoría en la filosofía del derecho no está presentando únicamente una actividad que se agota en la retórica, también muestra una idea regulativa con

${ }_{7}$ Carpintero, Francisco, La cabeza de Jano, Universidad de Cádiz, España, 1989, p. 10. 
pretensiones de guiar su comportamiento, el de la colectividad y la praxis jurídica. La filosofía del derecho no trata únicamente de clarificar conceptos, también refina el pensamiento y, con ella, las acciones. Laporta advierte que "es urgente tomar conciencia de que la filosofía del Derecho no va a sobrevivir si persiste en ser una vacía retórica arcaica basada en lecturas de segunda mano sobre problemas metafísicos de alcance municipal". ${ }^{8}$

\section{EL QUÉ DE LA PREGUNTA: ¿QUÉ ES EL DERECHO?}

El qué es en el fondo remite a la sustancia, es decir, (re)direcciona hacia algo que subsiste y permanece de alguna manera inalterable en la cosa que "objetivamente" se procura conocer.

La propuesta clásica del realismo reclama ingenuamente la objetividad de la investigación. A decir de esta, por medio de la investigación científica se describe al mundo tal cual se presenta, puesto que constituye una realidad observable, objetiva e independiente del ser humano. Dicha perspectiva se convirtió muy pronto en un referente, su difusión llegó a todos los campos del conocimiento. Era absurdo no defenderlo y un pecado mortal contradecirlo, y en su mayoría los investigadores estaban de acuerdo. La convención se hizo realidad, y el elemento subjetivo fue sustraído de la investigación. La buena nueva fue anunciada y se coronaba en los siguientes términos: el conocimiento constituye una expresión objetiva del mundo. ${ }^{9}$

La historia de la ciencia no ha sido una construcción lineal, siempre tuvo interrupciones abruptas, pausas inevitables que han pospuesto a segundo plano la búsqueda de esa representación objetiva llamada verdad, con la finalidad de averiguar el método adecuado que posibilite su consecución. En esta línea argumentativa, Frondizi ha señalado que "la historia de la ciencia y de la filosofía ha atravesado muchas veces una situación semejante en que el problema capital debe postergarse para dar entrada a un problema previo". ${ }^{10}$ Por lo tanto, el

\footnotetext{
${ }^{8}$ Laporta, Francisco J., en Doxa, 1/1984, p. 139.

${ }^{9}$ Por cierto, un antecedente -lejano por el tiempo y cercano por la forma en que está planteado- lo encontramos en el Teeteto, de Platón.

${ }^{10}$ Frondizi, Risieri, ¿Qué son los valores?, FCE, 3ra edición, México, 1972, p. 37.
} 
problema de la verdad científica se dejaba en suspenso y la atención se trasladaba momentáneamente a la cuestión metodológica.

Durante la Modernidad, la pausa y la pauta metodológica fueron instaladas por Descartes. Al margen de las tradiciones científicas y filosóficas, la formulación cartesiana llegó a ser el referente metodológico; su radicalidad demarcatoria entre lo que realmente es verdadero y lo que se presenta como tal sin serlo cautivó tanto a científicos como a filósofos. Para el inventor del cogito ergo sum, lo fundamental es el método, pues constituye el puente que posibilita la conexión entre pensamiento y realidad, entre cuerpo y mente; además, permite distinguir un problema real de un pseudoproblema. La significación de este último sentido implica la no admisión de emociones, sentimientos y demás manifestaciones singulares en el conocimiento.

Surge entonces uno de los grandes mitos del conocimiento moderno: la separación de lo que es primario y de lo que es secundario en la naturaleza humana, la separación entre la razón y las modalidades de su constitución. Lo que es individual, singular, histórico en sentido amplio se considera sin influencia y entonces debe ser neutralizado todo lo posible para garantizar un funcionamiento y un despliegue correctos de nuestro intelecto. ${ }^{11}$

Quien en cierta forma siguió los pasos programados por Descartes, la Ilustración y la promesa ilustrada fue Wittgenstein. Su Tractatus LógicoPhilosophicus, de 1918, cierra con la siguiente aserción: "De lo que no se puede hablar hay que callar". ${ }^{2}$ Vaya enérgica conclusión, pero ¿qué es de lo que no se puede hablar y es mejor callar? Lo que sugiere el primer Wittgenstein es que hay cosas que, desde el punto de vista racional, científico y lógico, no pueden ser explicados; por ende, no merecen atención reflexiva y es mejor que la razón y actividad filosófica se desentiendan y se aparten de ellas. Su propuesta filosófica implica que solo la lógica formal, el lenguaje matemático y las ciencias naturales

11 Ceruti, M., "El mito de la omnisciencia y el ojo del observador", El ojo del observador. Contribuciones al constructivismo, trad. Cristobal Piechocki, Gedisa, España, 1994, p. 37.

12 Wittgenstein, Ludwig, Tractatus Lógico-Philosophicus, trad. Jacobo Muñoz e Isidoro Reguera, Gredos, Madrid, 2009, p. 137. 
permiten una lectura objetiva de la realidad; todo lo que se produce fuera de la lógica, la matemática y la ciencia natural caen dentro del canon de la opinión subjetiva. Aquí están el arte, la estética, la justicia, la moral y otros. La respuesta que retrata la pregunta planteada es que de los recovecos del alma, de las emociones, de los sentimientos, de los comportamientos irracionales, del miedo, etc., no se sabe nada y es mejor callar. Ellos no tienen un espacio en la razón.

El segundo Wittgenstein, el de las Investigaciones filosóficas, se convierte en un terapeuta del lenguaje y extiende el espectro de la actividad filosófica, lo flexibiliza y deja a un lado el ideal del lenguaje objetivo, perfecto y ordenado con criterios de la lógica; en su lugar, propone la versión pragmática y convencional del lenguaje, cuya tesis central radica en que el significado del lenguaje es proporcionado por el uso que se da en un contexto de relación del ser humano entre sí y con el mundo. En consecuencia, la actividad filosófica está orientada a registrar la forma en el ser humano utiliza el lenguaje en diversas situaciones. Aquí, la cuestión es averiguar y describir qué hacen las personas con el lenguaje a nivel pragmático. Sin embargo, a pesar de su avance, sucede que la funcionalidad del quehacer filosófico se reduce al simple registro y examen de lo que hacen las personas con el lenguaje, no admite juicios de valor o juicios críticos que posibiliten la creación de un mundo distinto al que ofrece la realidad.

Para Carnap, un programa estrictamente filosófico y científico debe abandonar cualquier pretensión de trabajar con argumentos metafísicos y debe ceñirse exclusivamente al lenguaje de la lógica moderna. ${ }^{13} \mathrm{~A}$ decir de Carnap, las proposiciones que hace la ciencia son susceptibles de ser analizadas a través del lenguaje que provee la lógica, y el resultado es positivo, puesto que esclarece las conexiones lógico-formales de los conceptos que maneja la ciencia empírica y de su epistemología. Sin embargo, continua Carnap, no puede decirse lo mismo cuando se aplica la lógica a las proposiciones que se hacen desde la metafísica: el resultado es negativo, simplemente porque la metafísica opera con enunciados carentes de todo sentido. ${ }^{14} \mathrm{En}$ otras palabras, la metafísica plantea pseudoproposiciones.

\footnotetext{
${ }^{13}$ Carnap, Rudolf, "La superación de la metafísica mediante el análisis lógico del lenguaje", El positivismo lógico, FCE, México, 1965.

${ }^{14}$ Idem.
} 
Una proposición con sentido tiene que ser capaz de responder las siguientes cuestiones:

1) ¿De qué proposiciones es derivable $P$ y qué proposiciones pueden derivarse de $\mathrm{P}$ ?

2) ¿Bajo qué condiciones $P$ debe ser verdadera y bajo qué condiciones falsa?

3) ¿Cómo puede ser verificada P?

4) ¿Cuál es el sentido de P?

La formulación correcta es (1); (2) es la formulación de acuerdo con la terminología de la lógica; (3) la formulación de acuerdo con la terminología de la teoría del conocimiento; (4) de acuerdo con la filosofía. ${ }^{15}$

Transformar los enunciados de las ciencias empíricas al lenguaje lógico es viable. La causalidad que está presente en ellas en cuanto hecho constante y regular es una herramienta cognoscitiva fiable que permite - dadas ciertas condiciones-que se replique una situación. El valor epistemológico que provee juega un rol muy importante en la formulación y verificación de las proposiciones. De ahí que los enunciados científicos tengan una clara aceptación; se elaboran leyes generales con base en enunciados particulares que al final se traducen 0 encarnan en lo que se conoce como una ley científica. Mientras que el lenguaje metafísico tiene su singularidad, escapa a ser atrapado por el lenguaje lógico, pero esto no implica que sean proposiciones sin razón: tienen sentido y mucha racionalidad.

Felizmente el panorama ha cambiado, la correlación sujeto y objeto se ha flexibilizado. Hoy existe espacio para la subjetivación de lo objetivo y objetivación de lo subjetivo; junto a esto, el discurso científico y filosófico se ha modificado. Esto fue posible porque los elementos que antes se oponían y se neutralizaban ahora se integran: lo objetivo y lo subjetivo se juntan, se abrazan y se

15 Ibidem, p. 68. 
presuponen. Por ende, la producción del conocimiento depende de este resultado. No existe una representación objetiva de la realidad.

El qué de la pregunta qué es el derecho inevitablemente nos arrastra al ámbito de la metafísica, de lo subjetivo y de la objetivo — la realidad social-. La respuesta que se trate de brindar necesariamente transita entre estos elementos. Dichas cuestiones tienen conexión en el derecho.

No se puede analizar la pregunta qué es el derecho sin metafísica, sin lo subjetivo y sin realidad social. La pregunta qué es el derecho es una cuestión ontológica que implica argumentos racionales de carácter metafísico y social, así como criterios subjetivos del investigador. Lo metafísico de la pregunta está conectado con valores morales, con lo que es justo, con la naturaleza del ser humano, etc. Lo social de la pregunta está en que el derecho es una práctica social, responde a una realidad donde los seres humanos participan de ese fenómeno llamado derecho. Lo subjetivo se filtra inevitablemente debido a que el sujeto cognoscente se posiciona frente al objeto llamado Derecho y, según el interés que tenga y el objetivo que busca, procede a seleccionar información; hace distinciones, plantea valoraciones, efectúa jerarquizaciones y privilegia su punto de vista. No existe una descripción objetiva y dura de la realidad, no se presenta la división tajante entre sujeto y objeto.

La moderna filosofía del derecho ha respondido a la pregunta qué es el derecho desde tres variantes que pueden ser resumidas así: derecho como fenómeno social, según Hart; ${ }^{16}$ derecho como interpretación, según Dworkin; $;{ }^{17} y$ derecho como parte del razonamiento práctico, según Alexy. ${ }^{18}$

La primera es la perspectiva que comprende al derecho como fenómeno social. El rigorismo metodológico que emplean los representantes de esta postura circunscribe su objeto de estudio distinguiéndolo de la moral y la política. Hans Kelsen ${ }^{19}$ es influenciado por los planteamientos de Weber y Reichenbach,

\footnotetext{
${ }^{16}$ Hart, H. L. A., El concepto del derecho, trad. Genaro Carrió, Abeledo Perrot, Argentina, 2009.

${ }_{17}$ Dworkin, Ronald, Imperio de la justicia, trad. Claudia Ferrari, Gedisa, Barcelona, 2008.

${ }^{18}$ Alexy, Robert, Derecho y razón práctica, trad. Manuel Atienza, Pablo Larrañaga y otros, Fontamara, México, 1993.

19 Kelsen, Hans, Teoría pura del derecho, trad. Roberto Vernengo, UNAM-Porrúa, México, 1991.
} 
quien defendió magistralmente la pureza metodológica. Ross ${ }^{20}$ y Hart siguieron de alguna manera el discurso kelseniano.

Hart, influenciado por el segundo Wittgenstein, formuló los cimientos que actualmente orientan el desarrollo de la iusfilosofía. Su brillante perspectiva acerca del derecho y su alcance metodológico en la manera de hacer filosofía del derecho muy pocos la desconocen. Muchos tienen consciencia de la magnitud de los planteamientos hartianos. La concepción que presenta del derecho y su metodología iusfilosófica está enfrascada en un realismo que se ha defendido desde la filosofía y la ciencia en general desde el occidente. Este realismo insiste en aseverar que el producto de la observación es siempre independiente del ser humano, existe en sí y para sí. El conocimiento es capaz de representar un mundo autónomo e independiente del sujeto cognoscente.

\section{Bibliografía}

Alexy, Robert, Derecho y razón práctica, trad. Manuel Atienza, Pablo Larrañaga y otros, Fontamara, México, 1993.

De Zan, Julio, La filosofía social y política de Hegel, Ediciones del Signo, Argentina, 2009.

Descartes, Rene, El discurso del método, Trad. Manuel García Morente, AustralEspasa Calpe, Madrid, 1976.

Dworkin, Ronald, El imperio de la justicia, Trad. Claudia Ferrari, Gedisa, Barcelona, 2008.

- Los derechos en serio, Trad. Marta Guastavino, Ariel, España, 2014.

Hart, H. L. A., El concepto del derecho, Trad. Genaro Carrió, Abeledo Perrot, Argentina, 2009.

Hegel, W. F., Fundamentos de la filosofía del derecho o compendio de derecho natural y ciencia política, trad. Joaquín Abellán García, Tecnos, España, 2017.

Kelsen, Hans, Teoría pura del derecho, Trad. Roberto Vernengo, UNAMPorrúa, México, 1991.

Marmor, Andrei, Interpretación y teoría del derecho, Trad. Marcelo Mendoza, Gesdisa, España, 2000.

Watzlawick, Paúl y Krieg, Peter (comps.), El ojo del observador. Contribuciones al constructivismo, Trad. Cristóbal Piechocki, Gedisa, Madrid, 1994.

${ }^{20}$ Ross, Alf, Sobre el derecho y la justicia, trad. Genaro Carrió, EUBEA, Argentina, 1963. 